\title{
Environmental Pollution and Economic Growth in China: A Test of the Environmental Kuznets Curve
}

\author{
Jiaqi Hu, Adrian Hernandez-del-Valle, Miguel A. Martinez-Garcia \\ SEPI-ESE-Instituto Politécnico Nacional, Mexico City, Mexico \\ Email: ahdv@hotmail.com, jiaqimx@gmail.com
}

How to cite this paper: Hu, J.Q., Hernandez-del-Valle, A. and Martinez-Garcia, M.A. (2017) Environmental Pollution and Economic Growth in China: A Test of the Environmental Kuznets Curve. Journal of Geoscience and Environment Protection, 5, 92-100.

https://doi.org/10.4236/gep.2017.510008

Received: September 11, 2017

Accepted: October 22, 2017

Published: October 25, 2017

Copyright $\odot 2017$ by authors and Scientific Research Publishing Inc. This work is licensed under the Creative Commons Attribution International License (CC BY 4.0).

http://creativecommons.org/licenses/by/4.0/

\begin{abstract}
We apply a two pronged approach to analyze the presence of Environmental Kuznets Curve, EKC, in three types of emissions in the People's Republic of China from 1994 to 2014: a structural breakpoint analysis and a model based test. We apply it to $P M_{2.5}$, industrial waste and domestic water pollution time series, and find evidence of EKC in all three types of emissions that require appropriate policy.
\end{abstract}

\section{Keywords}

Economic Growth, Environmental Kuznets Curve, $\mathrm{PM}_{2.5}$, Domestic Water Pollution, Industrial Waste, China

\section{Introduction}

This paper examines the relationship between economic growth and environmental sustainability in the People's Republic of China, PRC, by empirically estimating environmental Kuznets curve (EKC) models using national data from 1994 to 2014. The results show that there exists an inverted-U shaped relationship as hypothesized by the EKC model between per capita GDP and per capita emissions (or discharges) of domestic water pollution, $P M_{2.5}$ microparticle emissions and industrial waste.

Specifically, we find that $P M_{2.5}$ has an $\mathrm{N}$ shape curve with two breakpoints (also found in literature as turning points, structural breakpoints, regime switches), SBs, at 9786.425 Yuan and 19880.32 Yuan. The EKC test applied to an interpolated $P M_{2.5}$ series indicates a Normal N type curve.

Industrial waste, $I W$, has what could become a two breakpoint EKC. The first breakpoint happens at 35300.37 Yuan with a pronounced change in slope going 
from 0.0751 to $0.0219, \mathrm{a}-71 \%$ change. If EKC is correct, then there must be a second breakpoint in the future where the slope becomes negative. The EKC test applied to this interpolated series shows an inverted $\mathrm{N}$ type curve. We forecast SBs but find no evidence of a second turning point.

Domestic water pollution, $D P$, presents a similar behavior as industrial waste: there could be two turning points with the first breakpoint happening at 19880.32 Yuan. The change in slope is not as pronounced as in the industrial pollution time series. In domestic water pollution the slope went from 1.4367 to $0.6089 \mathrm{a}-58 \%$ change. Interestingly, the first breakpoint in domestic water pollution coincides with the second breakpoint in the $P M_{2.5}$ time series. Both breakpoints happen in 2007. Applying the EKC test to an interpolated series of domestic water pollution we find the presence of a normal $\mathrm{N}$ type curve. As in the industrial waste case, we find no evidence of a second extrapolated SB.

In spite of the statistical evidence, we will see that the huge effort of the PRC government in curbing pollution raises the question of how high will per capita GDP have to grow in PRC in order to attain environmental sustainability; or worse, whether, GDP growth alone is enough to explain environmental sustainability. It may not be enough but we do find a long term equilibrium relation between GDP growth in the PRC and \$DP\$ and \$IW \$, they are cointegrated.

The paper is organized as follows, Section 2 presents a brief review of literature; Section 3, our methodology and data; Section 4 has our results; in Section 5 we forecast industrial waste and domestic water pollution in search of a second breakpoint but find none; Section 6 has our conclusions.

\section{The Environmental Kuznets Curve: A Brief Literature Review}

The environmental Kuznets curve, EKC, model has been one of the controversial topics in environmental economics in recent years. It hypothesizes that the relationship between income and environmental quality-which is often measured by the level of pollution-has an inverted-U shape: at relatively low levels of income, pollution increases and the environment deteriorates with rising incomes; beyond some turning point(s) (also found in literature as breakpoints or structural changes), pollution declines and the environment improves with income. This relationship was first noted in a series of empirical studies in the early 1990s Shafik and Bandyopadhyay [1], Panayotou [2], Grossman and Krueger [3], Selden and Song [4]. Subsequent empirical studies, however, showed that while the relationship holds in many cases, it cannot be generalized in many other cases. Further, researchers and policymakers are far from agreeing on the policy implications of the EKC model.

Grossman and Krueger [3] find, in a study of 32 American countries, that $\mathrm{SO}_{2}$ density and microparticles have an inverted $U$ relationship with per capita income. Cole, Rayner and Bates [5] find that only air pollution is related to per capita income. Egli [6] applies EKC to eight industrial pollution indicators in 
Germany and finds that $\mathrm{CO}_{2}$ and $\mathrm{NH}_{3}$ are related to per capita income.

The EKC hypothesis has been tested in the case of the PRC by several authors. Groot et al. [7] estimated EKCs for emissions or discharges of waste gas, waste water, and industrial solid wastes using provincial panel data from 1982 to 1997. They found that the emission-income relation depends on the type of pollutants and on how the dependent variable is constructed. The waste gas emission in terms of levels is found to follow an inverted-U pattern, but waste gas emissions in per capita or per unit of output terms, as well as waste water discharge, do not. Liu et al. [8] examined time series concentration data of various water pollutants in Shenzhen. They find that production-induced pollutants, as opposed to consumption-induced pollutants, support the EKC hypothesis. Shen [9] estimateda simultaneous three-equation model to address the endogeneity problem associated with per capita GDP and per capita pollution abatement expenses. Shen finds the EKC relationship for water pollutants but not for air pollutants. Auffhammer and Carson [10] find the EKC relationship between (log) per capita waste gas emissions and (log) total GDP in a two-way fixed effects model specification. Jiang et al. [11] show that there exists an inverted-U shaped relationship between per capita income and per capita emissions (or discharges) of wastegas from fuel burning and waste water, with a turning point at per capita gross domestic product of $\$ 12,903$ and $\$ 3,226$, respectively, in 2005 purchasing powerparity terms.

Peng and Xiaohong [12] show that EKC curves in China do not have the traditional inverted $\mathrm{U}$ shape. They propose that EKC curves of industrial waste water, industrial waste gas and industrial waste solid have an inverted $\mathrm{N}$ type.

\section{Methodology and Data}

To test the existence of EKC we apply two different approaches. First, we apply Bai-Perron structural breakpoint analysis to each of the pollutants time series, namely: industrial waste, $I W, P M_{2.5}$ particles and domestic water pollution, $D P$. We do this in order to determine if EKC can be proved directly on the raw data. Second, we expand the time series from 20 observations to 84 by using cubic interpolation. We do this in order to reduce the standard deviation on our estimations. We then estimate the following model based on Grossman and Krueger (1995)

$$
E=\beta_{0}+\beta_{1} Y+\beta_{2} Y^{2}+\beta_{3} Y^{3}+\mu .
$$

where $E$ is per capita emission or discharge of waste at time $t, Y, Y^{2}$ and $Y^{3}$ are per capita GDP, its square and cube at time $t$. The combinations of $\beta$ 's may render the following results:

- If $\beta_{1}>0, \beta_{2}<0$ and $\beta_{3}=0$, one finds the original inverted EKC $\mathrm{U}$ curve.

- If $\beta_{1}<0, \beta_{2}>0$ and $\beta_{3}=0$, we obtain a normal U shape.

- If $\beta_{1}<0, \beta_{2}=0$ and $\beta_{3}=0$, then environmental damage will exhibit a linear decrease. On the contrary, $\beta_{1}>0, \beta_{2}=\beta_{3}=0$ indicates linear increase.

- If $\beta_{1}<0, \beta_{2}>0$ and $\beta_{3}<0$, then environmental deterioration will show an in- 
verted $\mathrm{N}$ shape which implies that after several turning points emissions will tend to decrease;

- If $\beta_{1}>0, \beta_{2}<0$ and $\beta_{3}>0$, then it will present a normal $\mathrm{N}$ shape. This shape suggests that after several turning points emissions will increase.

Data is annual in 2010 constant Yuan. We obtained the data from the National Environmental Statistics Bulletin of Ministry of Environmental protection of the PRC. The GDP per capita was taken from the National Bureau of Statistics of China.

\section{Results}

Figures 1-3 show the results of the Bai-Perron test performed in R with library strucchange. The dotted lines represent the turning points or structural breaks in the series.

Note that the $\mathrm{N}$ shape is easily observable in the $P M_{2.5}$ time series.

The Bai-Perron analysis suggests that $I W$ and $D P$ may find a turning point later in time where the slope becomes negative and gives these types of emissions a definitive EKC inverted U shape.

Table 1 summarizes our findings regarding the EKC test, equation.

Equation (3.1) confirms the idea that $P M_{2.5}$ emissions in $P R C$ have a normal $\mathrm{N}$ shape. This indicates that after a period of reduction they tend to increase. (3.1) also indicates the presence of EKC for $I W$ and $D P$. The first have an inverted $\mathrm{N}$ shape that would suggest further decreases in industrial waste. This indicates that the second turning point where the slope becomes negative is not farfetched. However, $D P$ exhibits a normal $\mathrm{N}$ shape and this implies increases in domestic water pollution that will make it difficult to attain the second breakpoint.

Policy suggestions would require further action to curb $P M_{2.5}$ and $D P$ emissions in PRC.

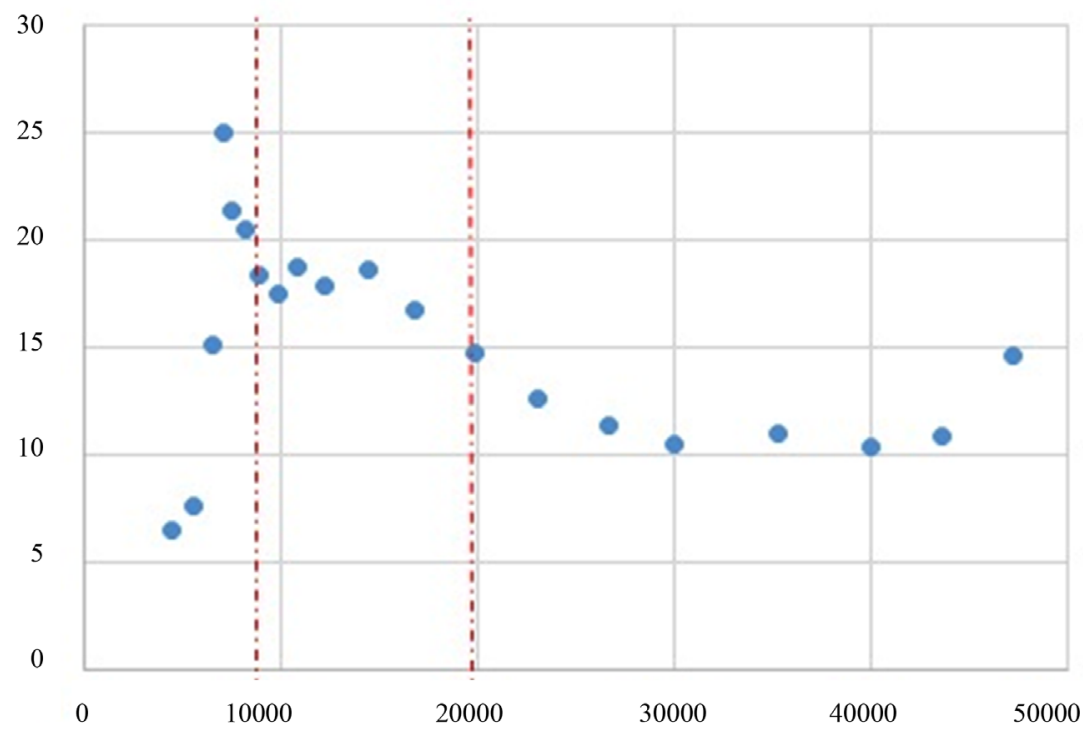

Figure 1. $P M_{2.5}$ and per capita GDP. Source: Own estimation. 




Figure 2. Industrial waste and per capita GDP. Source: Own estimation.

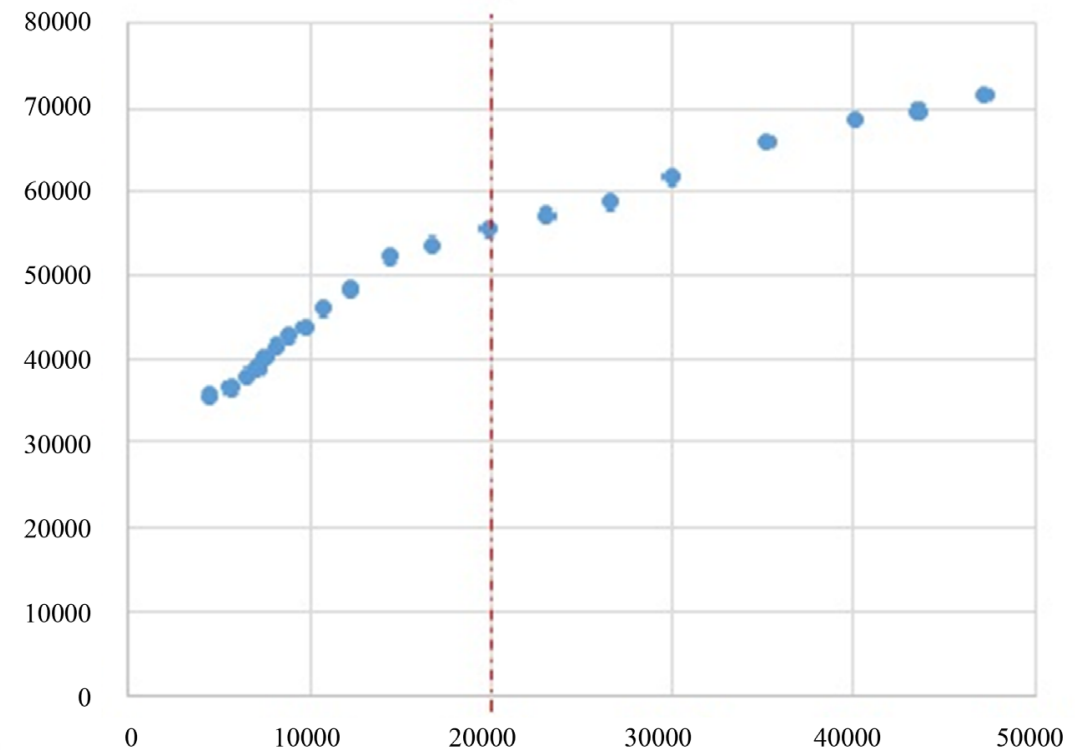

Figure 3. Domestic water pollution and per capita GDP. Source: Own estimation.

Table 1. EKC test applied to $I W, P M 2.5$ and $D P$.

\begin{tabular}{|c|c|c|c|c|c|}
\hline & Constant & $Y$ & $Y^{2}$ & $Y^{3}$ & Type \\
\hline$E_{J W}$ & $\begin{array}{c}608.64 \\
(0.0000)\end{array}$ & $\begin{array}{c}0.0109 \\
(0.4900)\end{array}$ & $\begin{array}{c}3.03 \mathrm{E}-06 \\
(0.0001)\end{array}$ & $\begin{array}{c}-4.17 \mathrm{E}-11 \\
(0.0001)\end{array}$ & Inverted $\mathrm{N}$ \\
\hline$E_{P M 2.5}$ & $\begin{array}{c}4.5056 \\
(0.0804)\end{array}$ & $\begin{array}{r}0.002497 \\
(0.0000)\end{array}$ & $\begin{array}{c}-1.28 \mathrm{E}-07 \\
(0.0000)\end{array}$ & $\begin{array}{c}1.71 \mathrm{E}-12 \\
(0.0000)\end{array}$ & Normal N \\
\hline$E_{D P}$ & $\begin{array}{c}23698.02 \\
(0.0000)\end{array}$ & $\begin{array}{c}2.6962 \\
(0.0000)\end{array}$ & $\begin{array}{c}-6.80 \mathrm{E}-05 \\
(0.0000)\end{array}$ & $\begin{array}{c}6.95 \mathrm{E}-10 \\
(0.0000)\end{array}$ & Normal N \\
\hline
\end{tabular}

Source: Own estimation. Note: p-value reported in parenthesis. 


\section{Forecasting SBs}

Figure 2 and Figure 3 depicting SBs in industrial waste and domestic water pollution suggest that there may be another turning point in the future where slopes finally become negative and EKC is attained. We test the existence of another future SB applying two approaches: an ARIMA technique and cointegration. For the ARIMA we do the following: First, we take the last stable-SB free-subsample of each $I W$ and $D P$; second, we build an ARIMA models for each $I W$ and $D P$; third, we forecast from the last SB to the fourth quarter of 2019; finally, we look for SBs in the predicted series applying the Bai-Perron test.

The SB in $I W$ happens in 2011 and the SB in DP in 2007. The ARIMA models for $I W$ and $D P$ were ARIMA $(1,1,0)$ and $\operatorname{ARIMA}(4,3,0)$ respectively. Figure 4 indicates that future SBs in industrial waste tend to increase the level of pollution rather than reduce it.

The red line is our forecast; the green line depicts the SBs and new higher levels in $I W$. The blue line is a residual: where the actual data is our forecast, and the estimates correspond to the Bai-Perron SB equation.

Figure 5 presents our results for $D P$. As observed, we find no evidence of a second turning point where the slope becomes negative.

We use a second method for predicting SBs. We find cointegration between $I W$ and per capita GDP. We build the vector error correction model, VEC; forecast $I W$ and again find no evidence of a downturn in the near future. Figure 6 shows our results.

Note: In order to forecast $I W$ using the VEC we first had to forecast per capita GDP. We found that per capita GDP was $I(3)$ and the model was ARIMA(5, 3, 8).

We also find cointegration between per capita GDP and $D P$. We repeat the procedure described for $I W$ and reject the hypothesis of downturns in $D P$. Figure 7 shows our forecast of $D P$.

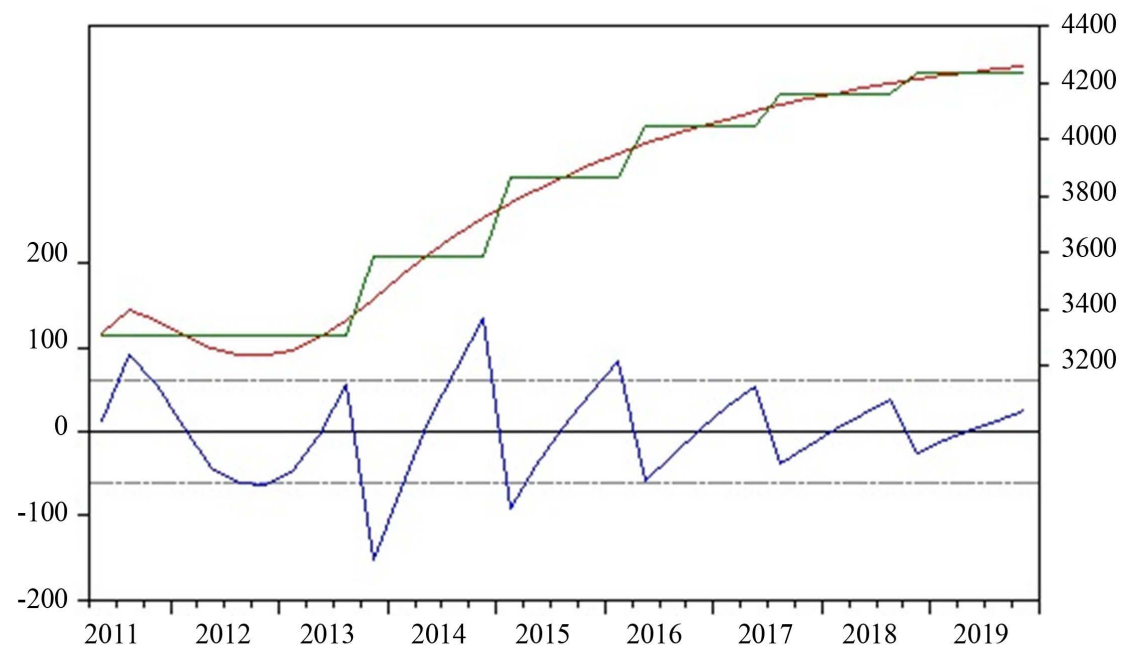

Figure 4. Predicted SBs in $I W$. Source: Own estimation. 




Figure 5. Predicted SBs in DP. Source: Own estimation.

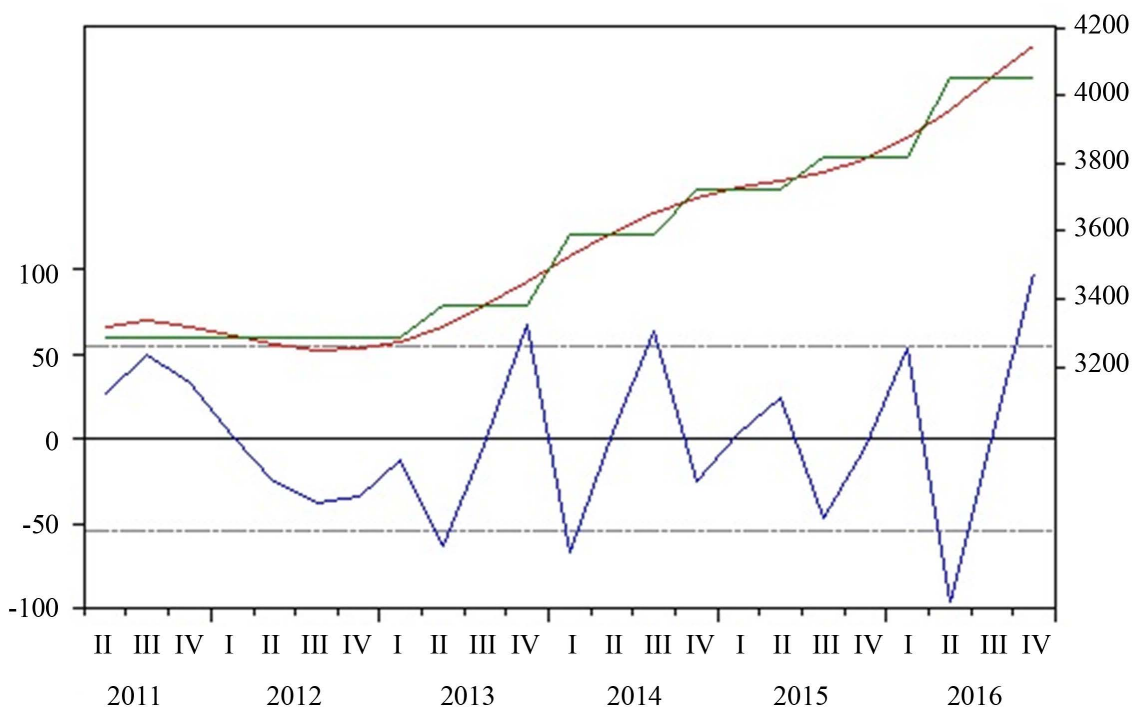

Figure 6. Predicted SBs in $I W$ using cointegration. Source: Own estimation.

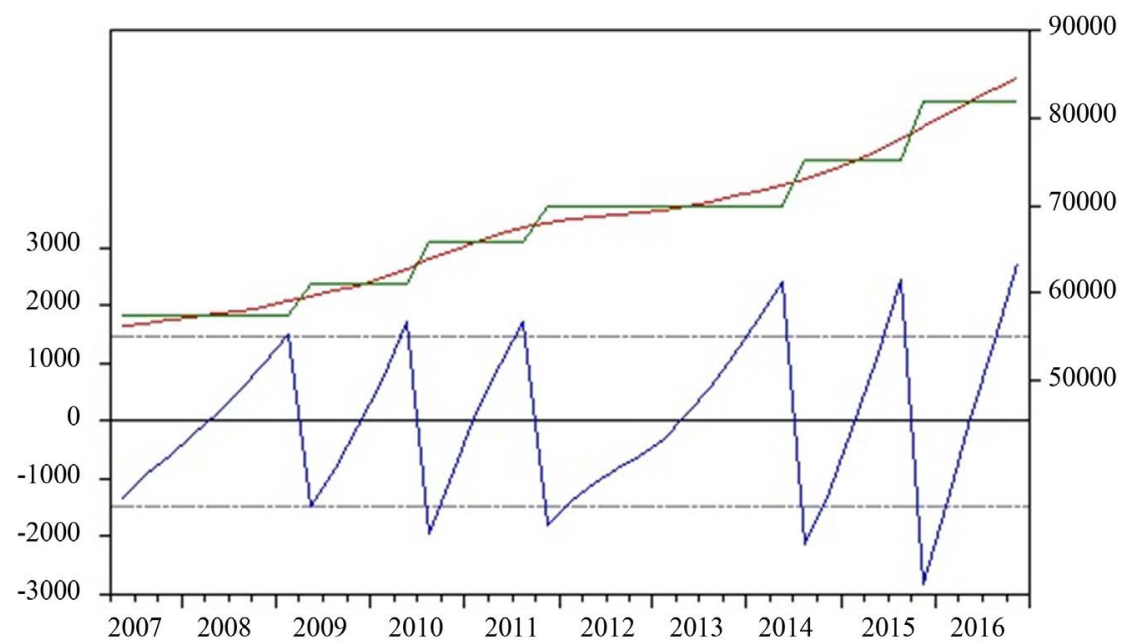

Figure 7. Predicted SBs in $D P$ using cointegration. Source: Own estimation. 


\section{Conclusions and Policy Implications}

We examine the relationship between economic growth and environmental sustainability in the PRC by testing the presence of EKC in three types of emissions from 1994 to 2014: a structural breakpoint analysis of $P M_{2.5}, I W$ and $D P$ time series; and a model based test.

Both tests indicate that $P M_{2.5}$ emissions tend to increase in PRC.

In regards to $I W$ and $D P$, the model based test, Equation (3.1), indicates that $D P$ has an upward trend albeit with a very small cubic coefficient so the increase is reversible if policy is appropriate. Finally, emissions of $I W$ have a downward trend, with a very small cubic coefficient which suggests that they should not be left to chance.

As mentioned in the Introduction $P M_{2.5}$ has turning points in 2001 and 2007; $D P$ in 2007; and $I W$ in 2011. According to the document Environmental protection in China (1996-2005) - colloquially known as the "White book"-of the Information Office of the State Council of the PRC, since 1998, the state environmental infrastructure as a national debt investment focus, led to a large number of social capital investment in environmental protection. Between 1996 and 2004, China's environmental pollution control investment reached 952.27 billion Yuan, accounting for 1\% of GDP over the same period. By 2000, 84 thousand companies had been closed in order to protect the environment and 12 thousand companies were certified with ISO14000. In 2005 another 2600 enterprises related to iron and steel, cement, ferroalloy, coking, papermaking, textile printing and dyeing were actively shut down because they were highly pollutant and were not in conformity with the industrial policy. In 2006, the environmental protection expenditure was formally incorporated into the national budget. In spite of all those positive actions, it seems that the effect of this great effort was a notable reduction in $P M_{2.5}$ and a mild reduction in $D P$; but a null effect on $I W$, which-only mildly-reacted in 2011.

From another perspective, $P M_{2.5}$ reacted to policy at 9786.43 and 19880.32 Yuan; $D P$ at 19880.32 Yuan; and $I W$ at 35300.37 Yuan. The difference between the first $P M_{2.5}$ and first $D P$ turning points is $103 \%$. The difference between the $I W$ and the $D P$ first turning point is $78 \%$-only to attain the first breakpoint. First turning points are notable because they imply that the pollutant has been only mildly curbed, so the question is, if EKC is correct, how high will Chinese per capita GDP have to go in order to finally control $D P$ and $I W$ ? Our forecasts find evidence of a second SB in neither IW nor DP. Another more troublesome question is whether per capita GDP growth is enough to account for environmental protection. It may not be enough, but we do find that there is an equilibrium long term relation between $I W, D P$ and per capita GDP growth, they are cointegrated. Forecasts of $I W$ and $D P$ based on cointegration do not suggest a downturn in pollution so further policy should be applied to curb them.

\section{References}

[1] Shafik, N. and Bandyopadhyay, S. (1992) Economic Growth and Environmental 
Quality: Time Series and Cross-Country Evidence. World Bank Policy Research Working Paper WPS904, Washington DC.

[2] Panayotou, T. (1993) Empirical Tests and Policy Analysis of Environmental Degradation at Different Stages of Economic Development. Working Paper WP238, Technology and Employment Programme, International Labor Office, Geneva.

[3] Grossman, G.M., and Krueger, A.B. (1995) Economic Growth and the Environment. Quarterly Journal of Economics, 110, 353-377. https://doi.org/10.2307/2118443

[4] Selden, T.M., and Song, D. (1994) Environmental Quality and Development: Is There a Kuznets Curve for Air Pollution Emissions? Journal of Environmental Economics and Management, 27, 147-162. https://doi.org/10.1006/jeem.1994.1031

[5] Cole, M.A., Rayner, A.J. and Bates, J.M. (1998) Trade Liberalisation and the Environment: The Case of the Uruguay Round. The World Economy, 21, 337-347. https://doi.org/10.1111/1467-9701.00133

[6] Egli, H. (2002) Are Cross-Country Studies of the Environmental Kuznets Curve Misleading? New Evidence from Time Series Data for Germany (April 2002). FEEM Working Paper No. 25.2002, Ernst-Moritz-Arndt University of Greifswald Working Paper No. 10/2001, Greifswald.

[7] Groot, H.L.F., Withagen, C.A. and Zhou, M. (2004). Dynamics of China's Regional Development and Pollution: An Investigation into the Environmental Kuznets Curve. Environment and Development Economics, 9, 507-537. https://doi.org/10.1017/S1355770X0300113X

[8] Liu, X., Heilig, G.K., Chen, J. and Heino, M. (2007). Interactions between Economic Growth and Environmental Quality in Shenzhen, China's First Special Economic Zone. Ecological Economics, 62, 559-570. https://doi.org/10.1016/j.ecolecon.2006.07.020

[9] Shen, J. (2006) A Simultaneous Estimation of Environmental Kuznets Curve: Evidence from China. China Economic Review, 17, 383-394. https://doi.org/10.1016/j.chieco.2006.03.002

[10] Auffhammer, M. and Carson, R.T. (2008) Forecasting the Path of China's $\mathrm{CO}_{2}$ Emissions Using Province-Level Information. Journal of Environmental Economics and Management, 55, 229-247. https://doi.org/10.1016/j.jeem.2007.10.002

[11] Jiang, Y., Lin, T. and Zhuang, J. (2008) Environmental Kuznets Curves in the People's Republic of China: Turning Points and Regional Differences. ADB Economics Working Paper Series. Asian Development Bank, Mandaluyong.

[12] Zhang, P. and Ma, X.H. (2007) The Empirical Study on Relationship between China's Economic Development and Environmental Pollution. Newspaper of Hunan Science and Technology College, 2007, 264-268. 